\title{
1. Epicurus: in outline and in history
}

Epicurus was born on the island of Samos as an Athenian citizen in 341 BCE (De Witt, 1954: Chs 2-6). It was during his formative years, 5-18 years of age, that Alexander the Great conquered the Persian Empire as far as modern-day India. Having first studied under Nausiphanes - a pupil of the founder of atomism, Democritus - Epicurus travelled to Athens at the age of 19 to begin a two-year military service. ${ }^{1}$ Aristotle died around this time. Military service done, over the course of 15 years Epicurus travelled around, teaching philosophy, before settling in Athens in 308 BCE. He soon established a school intended to rival Plato's Academy and Aristotle's Lyceum. Located outside the walls of Athens it was known as the Garden and for more than thirty years Epicurus presided over it as founding father. He himself died at the age of 70 but it was clear that his school would endure, having carved out a philosophy distinct from those which will also define the Hellenistic Age: Platonism, Aristotelianism, Stoicism, Cynicism, Scepticism.

This chapter has two aims.

First, it provides an overview of the basics of Epicureanism. It therefore reviews Epicureans' adaptation of atomism, their account of knowledge, and what they said about psychology in relation to psyche and the body. The rest of the chapter then outlines Epicurean ethics, with particular attention paid to religious belief, anxiety about death and the significance of friendship. The final section summarizes what we know of Epicureanism in the five centuries following the death of its founder and how both it and atomism revived in the early modern period.

The second aim is to equip us with a series of critiques, or what I will call 'puzzles', that will structure the analysis of Chapter 2. These puzzles are summarized at the end of the chapter.

For an overview of those philosophers who influenced Epicureanism, particularly its ethics, see Warren (2002). 


\section{ATOMISM AND BEYOND}

Epicureanism is the fullest expression and realization of the philosophy known as atomism to have survived from ancient times (De Witt, 1954: Ch. 9; Jones, 1989: 30-40). Formulated first at the end of the fifth century BCE by Democritus and Leucippus, atomists believed that everything which exists is made from indivisible units, or atoms.

With two exceptions, details of how and why Epicurus developed the ideas of the early atomists (see Morel, 2009; O'Keefe, 2010: Ch. 2) are less important than the central premise that everything (every inanimate object and animate being) is a compound of atoms (for example Epic II.44; DRN I.504-634). Humans, rocks, animals and stars are all built from atoms and they are all finite in duration because all compounds eventually break down, returning to their constituent parts. Yet since those atoms are themselves immortal and indestructible they will travel on to construct other objects and bodies in the future. Nature endlessly recycles itself (DRN I.216). The universe is therefore infinite in diversity because the number of atoms is infinite and so they can stick together in an infinite variety of ways (DRN I.959-1051). Our world is merely one of an infinity of worlds that can exist (DRN II.1049-76). In fact, Epicurus (Warren, 2002: 73) speculates that therefore there must be not just one cosmos but an unlimited number of 'cosmoi' inhabited by other beings (Epic II.45).

The two exceptions just mentioned are these.

Firstly, Epicurus thought that because atoms exist and movement is real, there must be empty spaces, an in-between-ness, into which atoms can move. Therefore, atoms and the objects they make depend upon something - or perhaps it should be called a 'non-thing', an absence between the atoms: a void. 'Nothing exists except atoms and the void', said Democritus, years before Epicurus (Barnes, 1987: 254-5). ${ }^{2}$ But for Epicureans the void would assume greater importance than it had for the early atomists in explaining generation and movement (Morel, 2009: $71-2,75-6)$.

The void is unbounded across space and time because, by definition, nothingness cannot be limited (DRN I.330-46). It is this which allows us to infer that atoms are similarly infinite across space and eternal across time - since for the void to be an absence it requires the presence of atoms to be between. If the void is unbounded, therefore, so are atoms.

2 In truth, this is slightly more poetic than a strict translation, but it is a common one difficult to avoid. 
Atoms and the void are found everywhere and everywhen. The motion of individual atoms through the void is halted when something is fashioned (some atoms coalesce into a compound) and is resumed when that something ceases to exist (the compound decays). Without the void nothing could exist, but because of the void nothing can exist forever. Hence, creation and destruction, birth and death, are inextricably entwined.

Secondly, how do we account for the fact that atoms can form compounds at all? And how is it that we live in a world which does not seem wholly deterministic? From the account given by Lucretius, Epicureans saw these questions as linked (Furley, 1999: 420-24; O'Keefe, 2009). Without a 'swerve' in the motion of atoms, reality would consist of nothing but the endless downward motion of disconnected atoms, like raindrops falling forever on their separate tracks through an insensible, featureless abyss (DRN II.217-25). This swerve makes collisions between atoms possible (O'Keefe, 2010: 26-31). It may also help to account for free will (see Chapter 2). The swerve denotes a randomness which disrupts the mechanistic, clockwork, deterministic sequence of cause-effect-cause-effect, perhaps enabling humans to have a capacity for self-determination and an opportunity to exercise their freedoms.

The world is therefore characterized by (1) atoms following motions that enable objects and people to form; (2) accidents, chance and contingency; (3) interventions made by free, conscious beings (Epic IV.133).

By incorporating an indeterministic swerve into his account, whose origin, nature and implications are unclear and so deeply contentious, Epicureans would leave themselves open to attack - as we shall see.

From this basic physics and metaphysics, Epicureans derived the rest of the thinking. Let's start with epistemology.

\section{KNOWLEDGE OF THE WORLD}

How do we achieve knowledge, according to Epicureanism (De Witt, 1954: Ch. 8; Jones, 1989: 24-7; Long and Sedley, 1987: 72-97; O'Keefe, 2010: Chs 4 and 10; Purinton, 1997: 91-6)? Through three faculties.

Firstly, sensations provide us with the most basic information about objects out there in the world. This occurs as the atoms of our senses impact with the atoms of those objects. These 'sense-impressions' give us access to what is real and actual. Sense-impressions can mislead but even misleading impressions indicate that something is there. 
Secondly, general concepts are the means by which we categorize, interpret, discriminate between, conceptualize and so give meaning to those 'sense-objects'. They enable propositions and descriptions of the world to be formulated. This is not to claim that general concepts are always right. Their identifications may be false or their applications improper. Sensations and conceptualizations must therefore interact repeatedly, with each as an iterative and recurring point of reference for the other. Sensations keep concepts attached to reality; concepts enable reality to be classified and apprehended.

Finally, the impact of atoms (the basis of our sensations) is experienced as either pleasurable (if the impact is harmonious) or painful (if it is abrasive) (DRN II.399-426). Honey is nice to eat, for example; therefore its atoms are mellifluous with the atoms of our taste-organs. So, our feelings of pleasure or pain offer criteria of how to act and how to live. We are motivated to increase what is harmonious and decrease what is abrasive (Epic VII.34). To seek what is pleasurable and avoid what is painful. ${ }^{3}$

There is more to human behaviour than our base, sensual drives, however. Humans habitually seek higher goods, with conflict resulting from disagreements over what those goods are and/or how they may be achieved. Epicureans try to cut through many of those conflicts by conceptualizing the highest pleasure in specific ways and recommending that we build our lives and societies around their pursuit: ataraxia and aponia (De Witt, 1954: 226-45; Mitsis, 1988: 51-8). We will discuss what these mean in Chapter 2.

In addition to those faculties, there may be things beyond our sense-experiences which we cannot encounter directly (like the atoms and void themselves). Here, we must proceed via hypotheses, inference and analogy and may always have to keep an open mind, accepting that several possible explanations of such phenomena can pertain.

That said, when hypothesizing about what lies beyond our senseexperiences we ought - open mind notwithstanding - to extrapolate from what we see around us. A material world must derive from material bits and pieces, i.e. the atoms from which everything is made possess extension (size, weight and shape). Explaining a materialistic world in terms of some immaterial substance (based upon spirit, soul, gods or

3 Some think that describing Epicureanism as a 'philosophy of pleasure' is too weak. Merlan (1960: 14-15) thought that 'joy' was a better term than 'pleasure' for all but the most sensual, bodily delights. Farrington (1967: 132) thought that something even loftier was required, such as 'blessedness'. By and large I will use 'pleasure' and 'happiness' as instances of the hedonic. 
any incorporeal substance) is fundamentally misguided, they argued (Whitmarsh, 2016: 92, 173-85). ${ }^{4}$ Epicureanism is thus a philosophy of materialism and empiricism where its epistemology - of sensations, general concepts and feelings - is founded on the movements and collisions of atoms.

This takes us to the Epicurean account of psychology and biology.

\section{PSYCHE AND BODY}

The psyche, Epicureans insisted, is part of the body (Gill, 2009: 126-8; also Konstan, 2008: Ch. 1). It lives when the body lives and dies when the body dies. These apparently harmless sentences capture much that was - and for many, still is - incendiary about Epicureanism.

For non-atomists and non-materialists (which meant nearly everyone) the soul denoted something that was immaterial, an incorporeal substance residing within but separate from the body. For Plato, on death the soul returns to the world of forms - the nature of which it forgets during its brief, Earth-bound residence within the body (Apolloni, 1996). This inspired the Christian conception, whereby the soul is that which survives the body's demise, returning to its immaterial origin. It flies back to God. To deny immateriality was to deny that the soul is incorporeal. It was therefore tantamount to denying the existence of gods and divinity, of immortal realms (heaven and hell) and so of life after death!

That Epicureans took a more complex and subtle approach to spiritual matters than this, as we see in Chapter 2, would often be ignored. For many of the devout, since materialism equals atheism you don't need to read any further. The denouncing and disparaging of Epicurus could now safely begin. ${ }^{5}$

Yet if Epicurean materialism neatly sidesteps the difficulty of explaining how immaterial and material substances interact, what alternative account does it offer?

The non-rational elements of humans are interconnected with the rational parts within the body. We exist as psychophysical wholes, possessing a unified agency. Which is to say that our elements coexist as a coherent system (Gill, 2009: 131-2, 137). Our beliefs are interwoven with our emotions and desires. Emotions guide reasons but, contra

4 The void is immaterial but it is not a thing, it is the emptiness between things.

5 Something which still occurs especially by the advocates of intelligent design (Wiker, 2002). 
Hume, ${ }^{6}$ our reasons can control our emotions and their excesses whether positive (euphoria) or negative (fears, hatreds) (O'Keefe, 2009: 149).

This coherence indicates that while psychological processes are ultimately the product of atomic movements they have to be understood in their own terms too. The psyche is not just a bunch of atoms temporarily glued together, because the structure of those atoms - their spatial arrangement - takes on a significance of its own. In short, those processes consist of dynamic spatial and relational properties ( $\mathrm{O}^{\prime}$ Keefe, 2009: 153-4), in that it is the systems and the structures of atoms which matter rather than atomic collisions alone.

There is a parallel to be drawn here with debates within Darwinian genetics (Fitzpatrick, 2005a: Ch. 6). At its most reductive, Darwinian genetics says that living beings are just collections of genes; macrovehicles or 'survival machines' which enable genes to propagate from one generation to another. On this reading, human civilization is merely a complex product of genetic interaction.

A non-reductive Darwinism says that organisms are more than their genes and more than a series of programmable, genomic algorithms. Societies and cultures enable organisms to transcend their biological origins. Similarly, Epicurus seems to be indicating that our psyches are 'emergent systems' which derive from, yet nevertheless exceed, their materiality. ${ }^{7}$ What matters is not just the material bits but the arrangement of the bits. The bits give rise to an arrangement but, by having its own dynamic, the arrangement also affects the bits.

Some scholars therefore think that Epicureans must have regarded the psyche as an emergent system (Gill, 2009: 133-8; Mitsis, 1988: 165-6; O'Keefe, 2009: 149). It is not simply that atoms give rise to spatial relations, because as well as atoms structuring the relations, the relations structure the motion of atoms also. The psyche is an ever-evolving network of interrelationships. Those relations thus have their own identity, integrity and dynamic, one which makes us self-aware, self-creating and self-determining. Humans have not only evolved due to the collisions of matter in motion, they have also self-evolved by constructing elaborate social environments that enhance the capabilities of the architects. We have built environments which enable us to build ourselves.

6 David Hume (1969: 460-61) maintained that reasons are the slaves of passions.

7 For a debate about genetics in relation to Epicureanism see Bobzien (2006: 215-20). 
To put it more simply, for Epicureans just as you can affect your sight by closing your eyes and so inhibiting the motions of your eye-atoms, so you can shape yourself (the composition of your psyche's atoms) by developing certain habits, adopting various practices or following particular social customs. We can do this individually (you can retrain your habits) and communally (by associating with others in cooperative partnerships and groups).

So because we are not limited to our inherited natures we possess the capacity for agency, virtue and responsibility. We mentally and physically reshape our pre-existing mental and physical characteristics. We are always more than our atomic and biological programming.

\section{BEYOND NATURE TO ETHICS}

Yet while we are more than our biological natures, nature always remains the soil from which our psychological roots grow. As such, for Epicureans there was nothing problematic about extrapolating an 'ought' from an 'is', a value from a fact (Jones, 1989: 49; Rist, 1972: 121). They did not offer a defence of their depiction of living beings as pleasure-seeking and pain-avoiding since they regarded this as an obvious matter of empirical observation, inferring from this that atoms hook on to one another in ways that are sometimes harmonious and sometimes discordant. Humans and nonhumans alike prefer things which are pleasing and avoid things which are disagreeable. The existence of diverse tastes is no hindrance to this reading. The fact that you enjoy eating something which I hate merely indicates that there are diverse ways of realizing pleasure. The goal itself remains the same.

We therefore have two components.

First, material nature is the source or ground of what we are: pleasure-seekers. Because of nature we are 'psychological hedonists' whose basic urge is to satisfy material desires. ${ }^{8}$ Secondly, there is more to our psychological composition than this alone. We are not the mechanized puppets of atomic motions because those motions include an element of randomness and indeterminacy, features which enable us to act freely.

The swerve is one of the most contentious elements of Epicureanism and so we explore it in the next chapter (Puzzle 1). But the basic point is that we are more than our natural drives. Some desires enable us to

8 There is a debate over whether Epicureans really were psychological hedonists. We touch on this in the next chapter. 
achieve the highest pleasure and some do not. Pleasurable activities which distract us from the highest pleasure are therefore self-defeating and so we should exert self-control over whatever it is (addictions, insecurity, fears, and so forth) that impels us towards them.

So, on the one hand, we are attracted to sensations and experiences which are pleasurable. On the other, we possess free will, such that some sensations and experiences can and should be prioritized over others. Thus, although we are natural beings we can control our desires as ethical beings. We can 'exceed' nature and improve upon it by making ethical judgements and acting accordingly. We do not have to seek just any kind of pleasure or self-indulgence. Our psychological hedonism underpins what we are but does not determine the character of our 'ethical hedonism'. It is in our nature to improve upon our nature. Though we seek pleasure we are not restricted by nature to the pleasures we seek nor the means by which we seek them.

Ethics therefore denotes the conscious interventions we make into both external nature (environmental contexts) and internal nature (drives and instincts). We do this by reflecting on the past and calculating the future outcomes of possible actions. That Epicureanism denotes an ethical hedonism has therefore been a source both of its philosophical achievements and of the misconceptions that have swirled around it for over two millennia.

\section{THE PLEASURES OF MORALITY}

\section{Nature and Necessity}

That distinction (between psychological and ethical hedonisms) is the central reason why Epicurean hedonism diverges from other forms of hedonism.

For the Cyrenaic school we go - and ought to go - wherever pleasurable experiences take us (Lampe, 2014; O'Keefe, 2002). ${ }^{9}$ Their emphasis is on the sensual and the immediate. If on Monday you receive pleasure by eating a cake and on Tuesday by starving yourself, then so be it.

But for Epicureans there is a potential conflict between the nature which makes us and the nature we try to make. The fact that we, unlike nonhumans, are not destined to obey whatever our fundamental drives

\footnotetext{
9 The Cyrenaics preceded Epicureanism.
} 
impel us to do gives us an ethical dilemma to solve. Which pleasures should be deferred in order that their enjoyment may be intensified (Warren, 2014: 176-86)? Which pleasures realize the highest pleasure and which are self-defeating?

Yet that dilemma is also a source of our strength and a sign of our autonomy. The being who must ask 'what is the right thing to do?' is also the being who can do the right thing. ${ }^{10}$ Our freedom is both disease and medicine. We are therefore entitled to go from a fact (we are pleasureseekers by nature) to a value judgement (we ought to seek the highest pleasure) but the transition requires careful deliberation (Epic IV.128-30).

However, the critics of Epicureanism have often found it convenient to smooth over the distinction between Cyrenaic and Epicurean approaches, whether through malice (discrediting the latter by association with the former) or simple ignorance (see Jones, 1989: 139-41, 152-3).

In fact, some critics might be even more dismissive of the Epicurean approach, for example such was arguably the case with Plutarch (Tsouna, 2016). If hedonism denotes pleasure-seeking, then, it might be claimed, at least the Cyrenaics had the courage to advocate that whatever pleases you is acceptable; for example if gluttony makes you happy then have at it. But, by distinguishing between acceptable and unacceptable pleasures, the Epicureans risked entangling themselves in a complexity they were unable to resolve. They were appealing to nature on the one hand and yet, on the other, abandoning nature when they disliked where our root instincts might lead us. They are trying to have their hedonistic cake while eating only some if it! Is this a fair criticism?

Epicureans grouped our desires into three categories (Epic IV.127-8, V.29; Jones, 1989: 46-7; Rist, 1972: 117-8). ${ }^{11}$

\section{- Natural and necessary}

These desires are those natural compulsions and appetites which are essential to life and well-being. The satisfaction of basic needs (for food, water, shelter) is obviously necessary for survival. Well-being, or flourishing, follows on from this. Once the means of life are fulfilled I can and should learn to live within my means. If I always want more then I will never have enough and so will remain permanently dissatisfied. But by having our natural/necessary desires and needs fulfilled, and not wanting more than it is

\footnotetext{
10 As Kant (2008: 94) said, 'ought' implies 'can'.

11 As Cicero (2001: 36) surmised, by 'desires' Epicureans seem to be speaking of what we typically call 'needs'. This should be remembered, despite the more contemporary association of desires with 'preferences' and 'wants'.
} 
necessary for me to have, I am free from disturbance and disorder. The highest pleasure is therefore tantamount to the removal of pain; that is, of anxiety and insecurity. We discuss this further in the next chapter as Puzzle 2.

- Natural and non-necessary

These desires involve pleasure and satisfaction but they are nonessential, for example luxuries. They might introduce variations into our experiences by offering a greater diversity of pleasures, but they do not add to the total sum of pleasure. I may find it pleasant to eat white bread today after a week of eating brown bread, but while a loaf of the former offers a different pleasure it does not satiate my hunger more than a loaf of the latter would do. These non-necessary desires therefore constitute the kinds of indulgences we ought to limit (through the exercise of self-control) so that we can concentrate upon the natural and the necessary. We investigate this category as Puzzle 3.

- Unnatural and non-necessary

These desires derive from beliefs which are wrong-headed, for example the desire for fame, wealth and power. They divert us from the goal of living a moral life and are likely to be a source of fears and anxieties; that is, things which are actually undesirable but which we cling to because we confuse them with the above, superior forms of desire. Two examples include the desire for the gods' approval and for immortality. Indeed, for Epicureans these desires conjoin and accompany two corresponding fears: the fear of gods (which people try to overcome through submission to the gods) and the fear of death. We discuss those fears at greater length under Puzzle 4.

We therefore have three options.

First, we can deny that pleasure has any role to play in moral judgements. This is what Kant (1996: 510-11) does when he says that, while we may experience pleasure for doing the right thing, we should not act for the sake of pleasure.

Secondly, we can be Cyrenaic hedonists and just indulge ourselves with abandon.

Or, thirdly, we can admit pleasure into our moral reasoning. There are many ways of doing this (we investigate an alternative to Epicureanism in Chapter 3) but the implication is that as both pleasure-seekers and ethical beings, the complexity invoked above is one which denotes what it means to be human. Epicureans should not be criticized, then, for acknowledging and reflecting upon it. 
Before moving on it is worth observing that the overview above has already sown the seeds of an account of human history (Jones, 1989: 48), such as that given in Lucretius. If transcending nature is what we do, then this implies external as much as internal nature. We work with the resources nature makes available to give ourselves what is required for life and comfort. In the early stages of civilization we are content with satisfying those basic desires because we are incapable of doing much else. But as we become adept at manipulating the world around us so we become more easily tempted by what lies beyond the natural and necessary, for example the pursuit of excessive wealth and power. Epicureans therefore offered an account of human progress which by no means takes progress for granted - Lucretius' De Rerum Natura is replete with evolutionary and social horrors (O'Keefe, 2010: 52-6).

\section{The Kinetic, the Katastematic and Ataraxia}

To claim that pleasure is good, then, does not mean imagining that all pleasures are equally good (Jones, 1989: 49-50). Epicureans therefore distinguished between two categories (Mitsis, 1988: 45-51; Preuss, 1994: Ch. 6).

Kinetic pleasures are non-necessary 'pleasures in motion' which depend upon change and process. Sensual pleasures of sight, touch, hearing and so forth seem to fall under this heading. A kinetic pleasure also seems to depend upon pain. If I enjoy reading a novel the enjoyment comes from anxious anticipation about how things will turn out. Will my favourite character die? Will the hero defeat the villain?

Katastematic pleasures are 'pleasures at rest' or in stasis, which implies an absence of disturbance or discomfort. They denote a state of being, involving equilibrium, calm, stability and completeness. Since they can be varied but cannot be quantitatively improved upon (as with the white loaf of bread) these are the highest pleasures and are sometimes known as 'static pleasures' (see Epic IV.130-32).

Though we should be wary of drawing an exact parallel, the kineticl katastematic distinction is presumably what J.S. Mill had in mind when he praised Epicureanism and devised his own distinction between higher and lower pleasures as a way of evolving Utilitarianism beyond Bentham, for whom all pleasures were equally good (Arangno, 2013: 201, 203-204; Wilson, 2009: 280). ${ }^{12}$

12 Hence Bentham's (1962: 253) famous assertion that pushpin is as good as poetry. 
But there is an important difference. Mill was more willing to identify the higher with one set of activities and the lower with another set. For Mill, poetry simply was superior to pushpin, as anyone who had experienced and been educated in the former could tell you.

For Epicureanism things are not quite that simple (Rist, 1972: 108109, 115). Even if the kinetic are lower (though this is a proposition we will interrogate in Chapter 2), this does not mean we should disdain them (as Mill seems to disdain pushpin) for three reasons.

Firstly, as materialists Epicureans were receptive to the delights which we experience when the senses are stimulated. A good game of pushpin enjoyed with friends is presumably better than reading bad poetry in solitude.

Secondly, therefore, even if kinetic pleasures do invite pain and disturbances, these may be worth experiencing. The short-term anxiety caused by reading my novel may be worthwhile if the result leaves me in a higher, long-term state of katastematic pleasure than I would have experienced otherwise.

Finally, the above arguments suggest that kinetic pleasures may be valuable for their own sake. Seeking variations in pleasure is important if a life is to go well. Epicurus' distinction between adding pleasure and varying pleasure may not hold if and when variation itself constitutes a form of addition. If we can derive simple, untroubling enjoyment from kinetic activities then they may add to life's richness. (This is an argument we pursue in the next chapter under Puzzle 3.)

The kinetic and katastematic are therefore intermingled to a degree that does not appear true of Mill's lower/higher distinction. What matters is not just what we do but the reasons why we do what we do (Jones, 1989: 51).

The Epicureans applied a term to the state of achieving katastematic pleasure which they seemed to have borrowed from Pyrrhonism, a branch of Sceptism (Warren, 2002: Ch. 7; also Kuzminski, 2008: 43-4; Preuss, 1994: 162-77): ataraxia. This has been translated in various ways: tranquillity, untroubledness, harmony. Ataraxia implies freedom from want (having basic needs satisfied) while possessing a delusion-free attitude towards desires, preferences, hopes and fears (Epic II.81-2; IX.136). If we have what we need and do not need more than we can reasonably have then we will be free of pain; that is, mental and bodily anxieties. Ataraxia implies a lack of things to lack. It means not being deprived of that which the body and mind need, while not possessing desires which, because they can never be realized, constitute a source of endless frustration. 
As we will see (Puzzle 2) there are three key questions here. First, is ataraxia a presence or an absence? Does it imply the acquisition of a state of being, or is it a disinvestment of whatever causes pain? Secondly, is freedom from mental pain (ataraxia) on the same level as freedom from bodily pain ${ }^{13}$ (aponia)? Is the mind higher than the body? Does ataraxia require aponia or is it distinct? Thirdly, what should we do when pleasures conflict? Are there any circumstances when we ought, morally, to prefer pain? Pending discussion of this in Chapter 2, I will use ataraxia as a catch-all term for the sake of simplicity. ${ }^{14}$

\section{GOD FEARING}

What are the chief fears and anxieties that we must free ourselves from if we are to achieve ataraxia? One is the fear of gods, of eternal punishment and divine retribution (Epic IV.133). The happy life is inconsistent with anxiety about the gods (De Witt, 1954: Ch. 13; Jones, 1989: 52-3; Konstan, 2008: 114-19; O’Keefe, 2010: 45-9, Ch. 16).

Why did the Epicureans propose this? They saw two possibilities, both of which cause anxiety. ${ }^{15}$

One is that the gods are interventionist, that they spend their time hovering over our shoulders, watching and judging everything we do like a divine parent or police officer (Rist, 1972: 147). Of course, through religious instruction and observance, it's more that you integrate the gods' commandments into your life. You monitor yourself. Nonetheless, some kind of communion with the Holy Supervisor is implied. What else do we expect when we kneel, place our hands together, close our eyes

13 This is a common translation of aponia, though Preuss (1994: 167-9) recommends 'freedom from toil and hardship' as more representative of what Epicurus meant.

14 Some readers will have observed the similarities between this aspect of Epicureanism and Buddhism. Both advocate a simple life of self-sufficiency in which we learn to be satisfied with what we have instead of constantly yearning for what we don't. For Epicureans the ideal was a familiar Hellenistic ethos of invulnerability, self-mastery and completeness (Mitsis, 1988: 1-3, 50-51). For Buddhists, releasing yourself from the cycle of desires is the path to nirvana. Despite their differing origins and contexts it is a puzzle why the similarities between Epicureanism and Buddhism have not been more thoroughly explored. Unfortunately, this is not an omission the present book will correct, either.

15 There is another debate we can safely ignore, over whether Epicurus thought of gods as real or as thought-constructs only (Konstan, 2011; Sedley, 2011). 
and pray, but that we will he heard and understood? The interventionist gods make us slave to their commands. Behave yourself, worship me and heaven awaits. If not, it's the other, hotter place for you.

The second possibility is that, while the gods observe and hear us, the universe is set on a predetermined trajectory. The gods settled the path of the world at its very inception and there is nothing we can do to alter its course. This is a source of anxiety because not only must we be subservient to the gods, as above, but our submission cannot have a practical outcome. We lack even the modest control and respect that the interventionist conception of divinity implies.

Despite the accusations of atheism which would plague Epicureanism for the next two millennia, Epicureans did not deny that the gods exist (Jones, 1989: 53-5). ${ }^{16}$ However, Epicurus did deny that they take any interest in human affairs. Indeed, it was conceivable that they barely noticed our existence or even that they were unaware of us completely! Why? Because for the gods to be the gods they must occupy the kind of state to which we should aspire: tranquillity. And how, exactly, would it be possible to maintain tranquillity if you are constantly being pestered by kneeling humans begging for favours (Rist, 1972: 146-7)?

But this still leaves room for the second predeterminist conception, does it not - perhaps something closer to the Stoic view? No. Recall that the swerve means that the world cannot be set on a purely deterministic course. And although the gods are themselves a product of atoms and the void (Rist, 1972: 148), they reside beyond the world. More accurately, since reality is infinite - because atoms and the void are infinite - there is not just one world, or cosmos, but infinite worlds. For Epicureans, the gods therefore reside in whatever exists between the worlds: the 'intercosmos' (Epic III.89).

Either way, the gods ought to be an object of admiration for us, not dread. Their undisturbed tranquillity can serve as a model for us, even though we cannot become gods ourselves. ${ }^{17}$ It is pointless to pray for the highest state of being because - by accepting Epicurean teaching, as it happens - you are already capable of providing this for yourself (Rist, 1972: 156). Ataraxia is the highest state of being we can attain, and certainly does not require submission to a divine realm.

16 How is this admission consistent with Epicurean materialism? The suspicion that Epicureans were atheists trying to head off charges of atheism dates back to antiquity (Cicero, 1998: 32).

17 In ancient mythology gods and humans not only conversed but sometimes swopped places. The Romans believed that it was possible for certain mortals the rich and powerful - to become gods. 
However, the Epicureans additionally maintained that religious observance and practice was perfectly acceptable. Shorn of delusions, e.g. the fears caused by misleading beliefs about the gods, the benefits of religious participation could remain as an important aspect of communal integration (Rist, 1972: 156, 159-60). Following social conventions was fine if they embodied and enhanced the benefits of friendship and so long as you understand that they are based upon nothing more solid than illusions and acts of social imagination.

\section{FEARING DEATH}

The second great misconception hindering ataraxia is anxiety about death (Epic IV.125; Konstan, 2008: 45-7, 50-53; O'Keefe, 2010: Ch. 17; Warren, 2004, 2009; also Burley, 2010).

Much of our fear about death, the Epicureans said, derives from a misunderstanding of the gods, for example that eternal damnation awaits the insufficiently pious. Take away that delusion, and fear of death should be dispelled too, no? Yet things aren't that simple of course. Even if we can put religion to one side, isn't it rational to fear your own future non-existence (death) and the transition from life to non-existence (dying)?

Death is not to be feared, the Epicureans insisted, precisely because it is non-existence and therefore other than what you are. Where death is, you are not; where you are, death is not. 'Death is nothing to us', they insisted (Epic IV.124). Because the soul/psyche is material, it will perish along with the rest of your body.

Lucretius invokes his famous symmetry argument at this point (DRN III.830-42; Simon, 2009). You don't remember anything which happened before your birth, do you? The fact that you did not experience the Black Death in the fourteenth century is not a source of loss or anxiety, is it? Then why should the non-existence after your death be any different from the non-existence which preceded your birth? The fact that you anticipate the former is unimportant. Death is as natural as life itself. With the correct beliefs, then, you can conquer any anticipatory anxiety. If you allow me to mash Vladimir Nabokov and Samuel Johnson together we might claim the following: one eternity of darkness is very much like another. ${ }^{18}$ So, stop worrying.

18 Nabokov (2000: 5) said that we constitute a 'brief crack of light between two eternities of darkness'. Johnson (Berglund, 2014: 8) observed that 'One blade of grass is very much like another' - I am paraphrasing slightly. 
And although dying can be painful the Epicureans believed that either the pain will be intense and short or longer in duration but less intense. Either type of pain is endurable, in other words. Epicurus himself was reported as being happy in his final weeks, despite being in physical distress, by reflecting upon a lifetime of satisfying memories.

Clearly, these views about gods and death require some consideration and we do so as Puzzle 4.

\section{POLITICS VERSUS FRIENDSHIP}

What memories did the ailing Epicurus recall? His philosophical work, no doubt, especially since he regarded philosophy as a shared, communal endeavour.

Marriage and parenthood were not prohibited, but Epicureans did not strongly recommend them either (Epic VIII.119; DRN IV.1058-1191). These were natural impulses but unnecessary to the attainment of pleasure. Indeed, passionate relationships were likely to be sources of anxiety. Most people are surely aware of how often love is accompanied by jealousy, insecurity and, sooner or later, a decline in intensity of the feelings we experienced in those first intoxicating months. For Epicurus, the simple life of self-sufficiency implied not being excessively dependent on others (Epic IV.130).

Better to seek something less intense: companionship, friendship (Brown, 2002). People could not help but seek one another out, so friendship was inevitable. The best option, then, was to belong to a community of friends which enables you to achieve ataraxia (Rist, 1972: 130-32, Ch. 7).

But that meant the community of friends had to be relatively small (Epic 1.9-10). Friendship takes time and effort. The more friends you have the 'thinner' each bond is likely to become. For Epicureans, the idea that you could be friends with a multitude of people in a polis was nonsense. They derided Aristotle's (1988: 3) depiction of man as by nature a 'political animal'. We may be communal animals, Epicureans rejoined, but politics is typically a source of what is anti-communal: self-serving ambition, power games, abuses of office, civil conflict, dictatorship (Epic VIII.119; O’Keefe, 2010: 145-6).

Epicureans therefore invoked and, indeed, inspired what would later be called the 'social contract', both as a way of explaining how societies developed and as a way of limiting the scope of political associations (O'Keefe, 2010: 143-6). Politics was, at best, a contract for mutual advantage. If you could not be friends with a mass of people, the only 
viable alternative was a formal, legalistic agreement to live and let live (Farrington, 1965: 31). Once the social contract assures your personal security and the security of your community of friends, you can concentrate upon the business of attaining the highest pleasure. This leaves a big question mark over what role, if any, justice is to play in an Epicurean society. We will consider this, along with a key question about self-interest and Epicurean friendship, under Puzzle 5.

Therefore, the Epicurean ideal seems to have been the sparsely inhabited landscape of the ancient world.

This may also be why Epicurus recommended participation in religious practices. Observing commonly accepted laws and customs was a way of living a life untroubled by political conflicts, in other words go with the flows of the crowd rather than standing out and inviting unwelcome attention. 'Live hidden' or 'live unnoticed' was a maxim Epicurus enjoined upon his followers. It did not imply living a solitary, hermit-like existence since, as noted above, friends and companionship were important (Mulgan, 1990). But it might imply a certain amount of simulation: publicly pretending that the customs you observe have meaning and reality while knowing that they are valuable merely as social constructions capable of bringing people together harmoniously. Living hidden implied living a quiet life among those who (wrongly) imagined that the gods were watching and listening. ${ }^{19}$

\section{THE NEXT FIVE CENTURIES AND BEYOND}

Following the death of Epicurus, the Garden was run by a succession of figures who, over the next century and a half, would establish Epicurean schools in cities across the Eastern Mediterranean.

In the following century, two significant figures emerged. Though barely any of his work has survived, Philodemus (approximately 110-30s BCE) was known to be a gifted popularizer of Epicurean ideas among the Romans. We are more fortunate with the poet Lucretius (approximately 90s-55 BCE) (Godwin, 2004). At almost 7500 lines, his De Rerum Natura provides the longest overview of Epicureanism to have survived.

Another important source of information dates from the next decade or so after Lucretius' death. In the final years of his life when, disillusioned

19 So the Epicurean should be true to his own beliefs but not seek to overthrow social customs since this would create disturbances inimical to happiness. That said, Epicurus seems to have gone out of his way to be provocative, at least to other philosophical schools. 
at the demise of the Roman Republic, he turned more to philosophy, the politician and orator Cicero composed several works examining Epicureanism. Cicero himself was eclectic, professing no strong allegiance to any philosophical school (Nicgorski, 2016). He demonstrates a lack of sympathy towards Epicureanism in three works: De Finibus (dealing with the ends of human action), De Natura Deorum (exploring the nature of the gods) and the Tusculan Disputations (practical questions of happiness, pain and death). Despite this lack of sympathy, modern scholars rely upon Cicero as a means of understanding Epicureanism. One of his friends and main correspondents, Atticus, was an Epicurean and perhaps inspired Cicero to be relatively fair-minded in his appraisal. Cicero certainly had high regard for Lucretius.

During this same period (70-19 BCE) the poet Virgil began his career under the influence of Epicureanism (Jones, 1989: 81-3). The Georgics, in particular, articulates an Epicurean view of nature. Virgil abandoned Epicureanism later, however. As the Republic gave way to the Imperial state under Augustus his emphasis shifted to one of duty and hierarchy, in The Aeneid, rather than pleasure and community.

Not surprisingly, at the same time Stoicism became the defining philosophy of Rome - though Seneca incorporated crucial elements of Epicurus into Stoicism (Erler, 2009: 49-50). Unlike Cicero, the historian Plutarch (approximately 50-120 CE) does not pull his punches. Epicureanism is heavily criticized in his ethical works, often to the point of caricature (Kechagia, 2011). Epicureanism would later persist as a reference point for humanists like Lucian, but it was no longer flourishing.

Epicureanism's relationship to early Christianity is particularly interesting, then (De Witt, 1954: 31-2). In most respects they were adversaries, given the extent to which Epicureans were critical of orthodox religious beliefs (Jones, 1989: 96-106). Yet early Christians may also have used Epicureanism as something of a foothold (Erler, 2009: 60-64). The latter's scepticism towards political engagement was palatable to those who emphasized spirituality over secularism and it was also a useful weapon against the kind of superstition for which Christians could portray themselves as the remedy (Jones, 1989: 110-13, 115-16). The Christians may have seen 'salvation' as a superior, religious equivalent to Epicurus' notion of philosophy as therapy. In middle of the third century, then, over five centuries after its founding, the Garden still existed. However, during the next two centuries, with the decline of the Roman Empire and the eventual dominance of Christianity, Epicureanism (along with Aristotelianism and Stoicism) all but vanished (Frede, 1999: 795-6).

Ancient classical culture and philosophy now lay dormant for ten centuries (Jones, 1989: Ch. 5). On the few occasions he was referred to at 
all, Epicurus was associated with lust, gluttony, sensualism and heresy. In Canto X of the Inferno, Dante depicts coffins which, though currently unsealed, would eventually imprison Epicureans forever. Since they insisted that the soul and the body are one, let them spend all eternity with their decaying flesh.

But those coffin lids were soon set to burst open again. Classical culture was rediscovered by those, the humanists, dedicated to Greek and Roman art and thought. What may have been the last surviving copy of De Rerum Natura was discovered in 1417 (Greenblatt, 2011). It is also probable that Lives of the Eminent Philosophers, by Diogenes Laertius, ${ }^{20}$ had survived throughout the intervening period and this now received its first Latin translation in 1430-31. It is to Diogenes' Lives that we owe the existence of the few works attributed to Epicurus himself.

Epicureanism would attract scholarly attention over the next two centuries, though this would be on nowhere near the same scale that had greeted the revival of Aristotelianism in the twelfth and thirteenth centuries (Jones, 1989: 155-8). Lucretius was admired as a poet but the actual ideas he defended received little more than a shrug of the Renaissance shoulders at best, or continued hostility at worst (Johnson, 2006). In the sixteenth century, Michel de Montaigne was sceptical of Epicureanism, ${ }^{21}$ though Erasmus would be more sympathetic (Jones, 1989: 160-65).

It is with the birth of modern science that Epicurus rises to intellectual prominence above Aristotle (Baker, 2007; Johnson and Wilson, 2007; Wilson, 2008; 2009: 269-73). Giordano Bruno would reject Aristotle, embrace atomism and be burned to death by the Inquisition as a result (White, 2007: 39-41). Galileo would follow his inspiration while managing to avoid his fate (White, 2007: 164). The next crucial figure was Gassendi (1592-1655) who, having also rejected Aristotelian methods, drew extensively upon Epicurean atomism - while altering parts of it to suit his Catholicism (Jones, 1989: Ch. 7). He postulated that when atoms hook on to one another they form what he termed molecules, thereby contributing to the investigation of both optics and chemistry.

Though he would be 'overshadowed by those whom he influenced' (Woolhouse, 1988: 48), Gassendi's impact would be considerable. Lennon (1993) notes how Locke was influenced by Gassendi to join the fray

$20 \mathrm{He}$ lived in the third century but the dates of his birth and death are unknown.

21 Doubting whether Epicurus really meant what he said about atoms. And note how Shakespeare frequently depicts Epicureanism as a philosophy of both sloth and indulgence, for example King Lear, Act 1, Scene 4, line 233. 
against a Cartesian view of both the natural and the political world Locke would be a key inspiration for the American Revolution.

It was his abhorrence towards the idea of a void that drove Descartes to theorize that the planets are swirled around in vortices, like flotsam in a whirlpool. In short, it's not the planets that move, it's the vortices they reside within (Gribbin, 2002: 115-17). Thus, until well into the eighteenth century, Cartesian science would be the preferred alternative for those who, ignoring mounting evidence that a vacuum could and did exist, rejected Newtonian ideas in which the idea of motion through a void was crucial. ${ }^{22}$ Newton's own response to atomism was ambivalent, ${ }^{23}$ but Gassendi undoubtedly helped clear the way for British science more widely (especially Robert Boyle) and for modern science itself (Kargon, 1964). Hovering above modernity's empirical preference for evidence, scepticism, rationality and observation - rather than the received opinions of religious and political authorities - we can discern the faint ghost of Epicurus.

Epicureanism would wane again over the next three centuries. Thomas Jefferson would characterize himself as an Epicurean in an 1819 letter to his former secretary and 'adoptive son' William Short (De Witt, 1954: 183-5, Ch. 15) but never incorporated a comprehensive critique into his philosophical and political work. Marx made Democritus and Epicurus the subjects of his doctoral dissertation and he would clearly retain a materialistic reading of history and economics. However, by turning to Hegel, Marx would adopt a teleological analysis to which Epicureans were hostile (Schafer, 2003). And, as noted above, Mill would cite Epicurus as an inspiration for his modification of hedonistic Utilitarianism (Wilson, 2009: 280). Following Mill, that other great Utilitarian philosopher of the nineteenth century, Henry Sidgwick (for example 2000: 80-82), advocated a universalized hedonism along Benthamite lines rather than the egoist hedonism of Epicureanism.

In the century and a half since Mill, interest in Epicureanism has occasionally revived among scholars, but on nothing like the scale that characterized its rediscovery in the early modern period.

22 Though we now know that a vacuum is not a void as the Epicureans would have understood it, the association between the two seemed obvious for several centuries.

23 See section 3 in https://plato.stanford.edu/entries/atomism-modern/ (accessed 3 September 2016). Also Jones (1989: 261, Ch. 8). 


\section{CONCLUSION}

As well as providing an overview of the basics of Epicureanism this chapter has also identified a series of ideas that we will need to investigate further if we are to understand its relevance to contemporary debates. I have referred to a series of critiques and in summary they are:

- Puzzle 1

The swerve and the question of free will.

- Puzzle 2

Natural and necessary desires and the significance of ataraxia.

- Puzzle 3

Natural and non-necessary desires and the role played by luxuries and indulgences.

- Puzzle 4

Fear and anxiety of the gods and of death.

- Puzzle 5

The nature of friendship.

Note that the concept of virtue will be a recurring theme across much of the above.

Chapter 2 now looks at these puzzles in greater detail. 